\title{
Organizational Learning Process in Single, Double and Triple Loop Companies in a Post-Crisis Situation in the Textile Sector in Tunisia
}

\section{Skhiri MO*}

Management and Entrepreneurship, University of Kairouan, Tunisia

\author{
Abstract \\ It is an "exploratory" research that tries to determine the most adopted organizational learning processes in post- \\ crisis Textile companies in Tunisia to guarantee their continuity and their survival. \\ The research methodology is summarized by the following steps: \\ - Exploratory qualitative study (non-formal because of the refusal to allow recorded interviews). \\ - Quantitative survey administered by questionnaire. \\ - Sample of 60 textile companies in Tunisia. \\ - In order to verify the reliability and validity of the scales of measurement the approach followed during this \\ research respects Churchill's paradigm. \\ - Assumptions were tested by regressions using SPSS 14 software. \\ This article aims to: \\ - Describe and develop an understanding of the single, double and triple loop learning processes used in the \\ management of post-crisis organizations. \\ - Determine the process typically adopted by leaders in post-crisis situations. \\ - To test the validity of the hypotheses. \\ - Provide benchmarks, methods, and tools for leaders to help them develop management plans to prevent, \\ respond to, and respond to crises.
}

Keywords: Organizational crisis; Organizational learning process in single loop; Double loop; Triple loop

\section{Introduction}

The concept of organizational learning is the topic of the day, in a world in perpetual evolution. This evolution is accompanied by the appearance of the company and how it responds to the difficulties encountered by the organization in a context where the environment is more turbulent and more severe.

Organizational learning thus forms a relevant long-term question, but at present it determines the subject of work that uses totally divergent notions. The concept of organizational learning lies at the heart of various fields namely: human resources management, sociology, cognitive psychology, theories of organizations, etc. In this sense it should be pointed out that several authors Shrivastava, Fiol and Lyles, Huber, Dixon [1-4] have been interested in the phenomenon of organizational learning and have established typologies of work on this theme. Among these disciplines, we will focus on the typology of the organizational learning processes of Argyris and Schon [5]. According to these authors, there are three levels of organizational learning that correspond to degrees of change, commitment, and questioning. These levels lead to single, double, or triple loop organizational learning processes, respectively [5] joins the reflections of several authors and supports the theoretical bases of our research subject. Organizational learning is really the most important issue for most companies today. Its management requires some willingness to learn: changing of the cultural base of the organizations concerned the implementation of new configurations and new instruments. All this cannot be done without real work or learning exercises that concern all individuals of a company, starting with his superiors. In this sense it must be said that learning is only feasible if it is deeply desired or sought after. This article aims to describe and develop an understanding of single, double and triple loop learning processes used in the management of postcrisis organizations.

\section{Simple loop organizational learning process}

The simple loop learning process results in companies being able to learn without completely changing their framework of action or their creative ideas. In this context Bateson [6] interpreted this learning process as "a change in the characteristic of error-correction responses within a set of options." The simple loop learning process is used by the majority of companies when managing small problems in line with pre-defined goals. In this sense, the process of learning in a simple loop results in maintaining the initial situation while adjusting to changes in the environment. According to the simple loop learning process presents shortcomings for the smooth running of the organization's

*Corresponding author: Skhiri MO, Assistant in Management Sciences, Management and Entrepreneurship, University of Kairouan, Tunisia, Tel: 77228 400/77 229 800; E-mail: olfaskhiri@yahoo.fr

Recieved December 06, 2017; Accepted December 12, 2017; Published December 18, 2017

Citation: Skhiri MO (2017) Organizational Learning Process in Single, Double and Triple Loop Companies in a Post-Crisis Situation in the Textile Sector in Tunisia. J Entrepren Organiz Manag 6: 219. doi: 10.4172/2169-026X.1000219

Copyright: (c) 2017 Skhiri MO. This is an open-access article distributed under the terms of the Creative Commons Attribution License, which permits unrestricted use, distribution, and reproduction in any medium, provided the original author and source are credited. 
business. To do this, they tried to set up the second-order learning process or the double-loop learning process.

\section{Double loop organizational learning process}

The double-loop learning process takes place when the organization decides to question its strategic goals as well as its organizational framework of action. According to this type of learning process is mainly based on "the introduction between unexpected stress, a breakup or a dose of disorder that forces the organization to change its way of thinking to meet it" [7]. Also mention that "the learning process of this type encourages the organization to re-examine its basic assumptions." In the same context, the double-loop learning process [5] also derives from [6] definition of second-level learning which defines it as "a correction in all the alternatives, as opposed to simple loop learning which essentially consists of modifying strategies within a frame of reference and standards of constant performance.” The double loop learning process requires a change in the frame of reference and a great concentration on the variation of the lines of success. This learning process usually stems from a disagreement between the methods used and the methods chosen. In this sense [5] define the double loop learning process as follows: "We will call double loop learning the organizational investigations that resolve the incompatibility of the organization's norms by setting new priorities and reallocating the weight of standards, or by restructuring the standards themselves with new strategies and presuppositions ".

\section{Triple loop organizational learning process}

The triple loop learning process is based not only on a change in the organization's principles and values, but also on a profound transformation of the organizational action framework. In this sense, [6] emphasizes that "the triple loop learning process requires a profound redefinition of one's own identity." In the same context, several authors also mention that "learning at the third level consists of integrating development processes into our analysis, our thinking, our problem solving methods and our philosophy. These are no longer objectives, strategies or structures of the company that we must change but rather ourselves and our way of thinking. It is the development of fundamental self-criticism, of questioning, of our cognitive structures, of defining the meaning that we want to give to our actions ". These three learning processes can be synthesized as follows:

- The first-order or single-loop learning process essentially results in the detection and correction of an error. At this level, the correction may consist in changing the pipes so as to adjust them to the situation and to exclude existing deviations from the norms.

- The second-order or double-loop learning process essentially results in the detection and correction of an error. At this level, the correction can consist in modifying the basic plan; it is thus characterized by a questioning of the organizational principles and a reorganization of the general framework of reference.

- The third order or triple loop learning process is essentially based on the combination of the two single loop and double loop processes.

- The triple-loop process thus translates into "the questioning of the identity and the reason for existing as an organization, as well as the cognitive structures of the leaders."

- Based on the theoretical concepts already developed, we can say that there are three organizational crisis learning processes that can be applied because of the level of change and questioning that the organization is willing to receive.

- First of all, the simple loop learning process opens up a refinement of existing systems, prevents the emergence of a similar crisis, and helps the organization to progressively adapt to changing environmental conditions.

- Secondly, the double-loop learning process attests to a questioning of the company's strategic objectives as well as the consideration of precautionary and anticipatory measures.

- Finally, the three-way learning process requires a serious dedication on the part of managers to encourage individuals in the organization to overcome the obstacles caused by the ways of thinking that pushed them into the crisis. The triple loop process is therefore based on a radical change in the organization and the cognitive structures of the leaders.

\section{Empirical Study and Results of Research}

\section{Hypotheses}

$\mathrm{H}$ : The process of learning in post-crisis situations is a threedimensional concept:

Ha: The most adopted learning process in post crisis situation is the simple loop process;

$\mathrm{Hb}$ : The most adopted learning process in post-crisis situations is the double-loop process;

Hc: The most adopted learning process in post-crisis situations is the triple loop process.

\section{Measuring the Variable Organizational Learning Process}

Argyris and Dufort $[5,8]$ point out that there are three levels of organizational learning, which correspond to varying degrees of change, commitment, and questioning. Which lead to single loop, double loop and triple loop organizational learning processes respectively?

\section{Measurement of the organizational learning process in a single loop}

The Simple Loop Organizational Learning Process is about adjusting, adapting, reorienting, maintaining the status quo, seeking stability through correcting mistakes or gradually changing the organization. This simple loop process allows the activity of the affected organization to be resumed, gradually adapting to changes in the environment without changing its strategic objectives $[5,8]$.

\section{Measurement of the double loop organizational learning process}

The double-loop organizational learning process is based on a more or less profound change in the organizational action framework, which encourages the organization to re-evaluate its basic assumptions $[5,8]$.

\section{Measurement of the organizational learning process in triple loop}

The triple loop learning process is based on the radical change of identity, purpose and existence as an organization, as well as the cognitive structures of leaders [8].

We developed 4 items to measure the learning process variable in a 
Citation: Skhiri MO (2017) Organizational Learning Process in Single, Double and Triple Loop Companies in a Post-Crisis Situation in the Textile Sector in Tunisia. J Entrepren Organiz Manag 6: 219. doi: 10.4172/2169-026X.1000219

Page 3 of 7

simple loop. We also created 2 other items that will be used to measure the dual loop learning process variable. Finally, we have 2 items to measure the triple loop learning process variable (Tables 1-3). The analysis of the eigenvalues and according to the Kaiser norms and the test of the elbow allow us to retain three dimensions gathering $73.44 \%$ of the variance. Therefore the concept of organizational learning is three-dimensional:

Axis 1: Double loop learning/questioning and modification of objectives.

\begin{tabular}{|l|l|l|}
\hline Single loop learning process & $\begin{array}{c}\text { Strongly } \\
\text { Disagree }\end{array}$ & $\begin{array}{c}\text { Strongly } \\
\text { Agree }\end{array}$ \\
\hline $\begin{array}{l}\text { 6-1 The organization has maintained the stability of } \\
\text { the initial operating system by gradually adapting to } \\
\text { changes in the environment. }\end{array}$ & & \\
\hline $\begin{array}{l}\text { 6-2 The organization detected and corrected the } \\
\text { error in making minor changes. }\end{array}$ & & \\
\hline $\begin{array}{l}\text { 6-3 The organization has put short term measures in } \\
\text { place based on pre-established objectives. }\end{array}$ & & \\
\hline $\begin{array}{l}\text { 6-4 The organization has acquired new skills without } \\
\text { questioning its framework of action and its founding } \\
\text { beliefs. }\end{array}$ & & \\
\hline
\end{tabular}

Table 1: Items Used for Operation analysis of the Single Loop Learning Process Variable.

\begin{tabular}{|l|l|l|}
\hline Double loop learning process & $\begin{array}{c}\text { Strongly } \\
\text { Disagree }\end{array}$ & $\begin{array}{c}\text { Strongly } \\
\text { Agree }\end{array}$ \\
\hline $\begin{array}{l}\text { 6-5 The organization has questioned its strategic } \\
\text { objectives, its standards and values its basic } \\
\text { assumptions. }\end{array}$ & & \\
\hline $\begin{array}{l}\text { 6-6 The organization changed its objectives, } \\
\text { reoriented his perception and his framework of } \\
\text { action. }\end{array}$ & & \\
\hline
\end{tabular}

Table 2: Items used for operationalization of the double loop learning process variable.

\begin{tabular}{|l|l|l|}
\hline Triple loop learning process & $\begin{array}{c}\text { Strongly } \\
\text { Disagree }\end{array}$ & $\begin{array}{c}\text { Strongly } \\
\text { Agree }\end{array}$ \\
\hline $\begin{array}{l}\text { 6-7 The organization questioned its identity, its } \\
\text { purpose and reason for existing as well as the } \\
\text { Cognitive structures of the leaders. }\end{array}$ & & \\
\hline $\begin{array}{l}\text { 6-8 There has been a radical transformation of the } \\
\text { affected system and behaviors of its leaders. }\end{array}$ & & \\
\hline
\end{tabular}

Table 3: Items used for operationalization of the triple loop learning process variable.
Axis 2: Learning simple loop learning/maintaining the system and correcting the error.

Axis 3: Triple loop learning /questioning the identity (Table 4).

In the end, out of the 8 initial items only 6 were retained. The others were eliminated according to the Statistical rules of a Kaiser above. The internal coherence coefficients (Cronbach's Alpha) for double loop learning challenge and objective modification dimensions, learning simple loop maintenance of The system and error correction, are respectively equal to 0.822 , and 0.76 and testify to good Consistency between items in each dimension. For our study, we will retain the three factors of the Organizational learning process concept.

\section{Test of Convergent Validity}

In order to test the convergent validity of the factors selected, we will calculate Pearson's bivariate Correlation indices between items of the same factor. Table 5 gives us the Pearson Correlation Matrix calculated for the 2 items of the Double Loop Learning/Questioning factor and modifying the objectives. It is found that all of Pearson's bilateral correlations are significant at the threshold of $1 \%$ (Table 5) we therefore conclude that there is a significant correlation between the items of the factor: Double loop learning/questioning and modification of objectives. We also showed the existence of significant correlations between the 3 items Factor Learning mere maintenance of the system loop and correcting the error.

We see that all bilateral Pearson correlations were significant at $1 \%$ (Table 6). It is therefore concluded that there was a significant correlation between the items of factor: Learning simple loop system maintenance and error correction.

\section{Organizational Learning Process}

\section{Organizational learning process in single loop}

A strong majority of respondents (95\%) used to maintain the original operating system by adapting gradually to environmental change ( 4 and 5 on a scale of $1=$ not at all agree $/ 5=$ agree). Similarly, the detection and correction of the error by making minor modifications have been-used by $98.3 \%$ of respondents, and $86.7 \%$ of respondents have used the introduction of short-term measures, based on preestablished goals. Furthermore, $71.7 \%$ of respondents were unable to acquire new skills without questioning their framework and their founding beliefs (Tables 7-10).

\begin{tabular}{|c|c|c|c|c|}
\hline \multirow[t]{2}{*}{ Items } & \multirow[t]{2}{*}{ Communality } & \multicolumn{3}{|c|}{ Matrix of components after rotation } \\
\hline & & $\begin{array}{c}\text { Double loop learning/ } \\
\text { questioning and modification } \\
\text { of objectives. }\end{array}$ & $\begin{array}{l}\text { Simple loop learning / } \\
\text { Maintaining a system for error } \\
\text { correction. }\end{array}$ & $\begin{array}{l}\text { Triple loop learning: } \\
\text { Questioning its identity }\end{array}$ \\
\hline $\begin{array}{l}\text { Double loop=challenging strategic Objectives, standards and } \\
\text { values and its basic assumptions. }\end{array}$ & 0,859 & 0,926 & $-0,028$ & 0,0243 \\
\hline $\begin{array}{l}\text { Double loop=modification of the objectives of the } \\
\text { organization, reorientation of its perception of its }\end{array}$ & 0,807 & 0,889 & $-0,093$ & $-0,089$ \\
\hline $\begin{array}{l}\text { Single loop=detection and correction of the error by minor } \\
\text { modifications }\end{array}$ & 0,665 & 0,309 & 0,749 & $-0,097$ \\
\hline Single loop=maintenance of the initial operating system & 0,613 & 0,154 & 0,744 & 0,188 \\
\hline $\begin{array}{l}\text { Single loop=implementation of short term measures based } \\
\text { on pre-established }\end{array}$ & 0,575 & $-0,079$ & 0,676 & $-0,334$ \\
\hline $\begin{array}{l}\text { Triple loop=questioning the identity, the purpose for existing, } \\
\text { the cognitive structures of } \\
\text { The leaders. }\end{array}$ & 0,888 & $-0,066$ & 0,045 & 0,939 \\
\hline Percentage of variance & & 29,637 & 26,380 & 17,435 \\
\hline Total & \multicolumn{4}{|l|}{73,441} \\
\hline
\end{tabular}

Table 4: Communality and Principal Component Analysis of Organizational Learning Processes. 
Citation: Skhiri MO (2017) Organizational Learning Process in Single, Double and Triple Loop Companies in a Post-Crisis Situation in the Textile Sector in Tunisia. J Entrepren Organiz Manag 6: 219. doi: 10.4172/2169-026X.1000219

Page 4 of 7

Items

App double loop=challenging strategic goals, standards and values and its basic assumptions Sig. (Bilateral).

App Boucle double=changing the organizational aims,

Reorientation of its perception and Its framework for

action, Sig. (Bilateral).

Questioning and changing goals.

${ }^{* *}$ Correlation is significant at 0.01 (bilateral).

Table 5: Correlations between two different items of factor Double loop learning process.

\begin{tabular}{|c|c|c|c|}
\hline Items & $\begin{array}{l}\text { App Single loop=Detection and error } \\
\text { correction by minor modifications. }\end{array}$ & $\begin{array}{l}\text { App single loop=Maintain initial } \\
\text { system of operation. }\end{array}$ & $\begin{array}{l}\text { App single loop=implementing } \\
\text { short-term measures based on } \\
\text { predetermined goals. }\end{array}$ \\
\hline $\begin{array}{l}\text { App single loop=Detection and Correction of } \\
\text { error by Minor modifications Sig. (Bilateral). }\end{array}$ & 1 & $0.554^{* *}$ & $0.439^{* *}$ \\
\hline $\begin{array}{l}\text { App single loop=Maintenance of initial operation } \\
\text { system Sig. (Bilateral). }\end{array}$ & $0554^{* *}$ & 1 & $0.738^{* *}$ \\
\hline $\begin{array}{l}\text { App single loop=easy implementation of short- } \\
\text { term measures based on already Planned goals } \\
\text { Sig. (Bilateral). }\end{array}$ & $\begin{array}{l}0.439^{* *} \\
0.000\end{array}$ & $\begin{array}{l}0.738^{* *} \\
0.000\end{array}$ & 1 \\
\hline
\end{tabular}

Single loop maintenance system and Error Correction.

${ }^{* *}$ Correlation is significant at 0.01 (bilateral).

Table 6: bivariate correlations between the items of factor learning process.

\begin{tabular}{|l|c|c|c|c|}
\hline & Frequency & Percentage & Agree Percentage & Cumulative Percentage \\
\hline Agree & 3 & 3 & 4.3 & 5.0 \\
\hline 4 & 36 & 52.2 & 60.0 \\
\hline Strongly agree & 21 & 30.4 & 65.0 \\
\hline Total & 60 & 87.0 & 100 \\
\hline
\end{tabular}

App single loop=maintain initial system of operation.

Table 7: Single loop learning: maintaining of the initial operation system.

\begin{tabular}{|l|c|c|c|c|}
\hline & Frequency & Percentage & Agree Percentage & Cumulative Percentage \\
\hline Agree & 3 & 1 & 1.4 & 1.7 \\
\hline 4 & 27 & 39.1 & 45.0 \\
\hline Totally agree & 32 & 46.4 & 46.7 & 53.3 \\
\hline Total & 60 & 87.0 & 100.0 \\
\hline
\end{tabular}

App Single loop=detection and error correction by minor modifications.

Table 8: Single loop learning: detection and correction of the error by minor modifications.

\begin{tabular}{|c|c|c|c|c|}
\hline & Frequency & Percentage & Agree Percentage & Cumulative Percentage \\
\hline 2 & 2 & 2.9 & 3.3 \\
\hline 3 & 6 & 87 & 10.0 \\
\hline Agree & 28 & 40.6 & 46.7 \\
\hline Totally agree & 24 & 34.8 & 40.0 \\
\hline
\end{tabular}

App single loop=implementation of short-term measures, based on pre-established aims.

Table 9: Single Loop Learning: implementing short-term measures based on predetermined goals.

\begin{tabular}{|l|c|c|c|}
\hline & Frequency & Percentage & Agree Percentage \\
\hline Agree strongly disagree & 22 & 31.9 & 36.7 \\
\hline 2 & 21 & 30.4 & 35.0 \\
\hline 3 & 14 & 20.3 & 23.3 \\
\hline 4 & 2 & 29 & 31.7 \\
\hline Totally agree & 1 & 14 & 95.0 \\
\hline Total & 60 & 87.0 & 17 \\
\hline
\end{tabular}

App single loop=new skills without modification of the founding beliefs.

Table 10: Single loop learning: learning new skills without changing founding beliefs.

\section{Organizational learning process double loop}

$66.7 \%$ of managers say they have questioned the strategic aims, standards, values and basic assumptions of their organizations. (4 and
5 on a scale of $1=$ not at all agree/5=strongly agree). Similarly, $60 \%$ used the modification of the goals of their organizations realignment, their perception and its framework for action (Tables 11 and 12). 
Citation: Skhiri MO (2017) Organizational Learning Process in Single, Double and Triple Loop Companies in a Post-Crisis Situation in the Textile Sector in Tunisia. J Entrepren Organiz Manag 6: 219. doi: 10.4172/2169-026X.1000219

Page 5 of 7

\begin{tabular}{|c|c|c|c|c|}
\hline & Frequency & Percentage & Agree Percentage & Cumulative Percentage \\
\hline Agree doesn't agree at all & 9 & 13.0 & 15.0 & 15.0 \\
\hline 2 & 6 & 8.7 & 10.0 & 25.0 \\
\hline 3 & 5 & 7.2 & 8.3 & 33.3 \\
\hline 4 & 22 & 31.9 & 36.7 & 70.0 \\
\hline \multicolumn{5}{|l|}{ Totally agree } \\
\hline Total & 18 & 26.1 & 30.0 & 100.0 \\
\hline
\end{tabular}

Double loop process=dual challenge of strategic goals, standards and value it's basic Assumptions.

Table 11: Challenging strategic goals, standards, values and organizational assumptions.

\begin{tabular}{|c|c|c|c|c|}
\hline & Frequency & Percentage & Agree Percentage & Cumulative Percentage \\
\hline Agree & strongly disagree & 9 & 13.0 & 15.0 \\
\hline 2 & 8 & 11.6 & 13.3 \\
\hline 3 & 7 & 10.1 & 11.7 \\
\hline 4 & 16 & 23.0 & 26.7 \\
\hline Totally agree & 20 & 29.0 & 30.0 \\
\hline Total & 60 & 87.0 & 100 \\
\end{tabular}

Dual Loop Process=modification of the organization's goals, reorientation of its perception and its framework for action.

Table 12: Change of the goals of their organization's realignment, its perception and its Framework for action.

\begin{tabular}{|l|c|c|c|c|}
\hline & Frequency & Percentage & Agree Percentage & Cumulative Percentage \\
\hline Agree & strongly disagree & 25 & 36.2 & 41.7 \\
\hline 2 & 27 & 39.1 & 45.0 \\
\hline 3 & 8 & 11.6 & 13.7 \\
\hline Total & 60 & 87.0 & 100.0 \\
\hline
\end{tabular}

App Triple loop=questioning of identity, purpose to exist and cognitive structures of leaders.

Table 13: Questioning the identity, purpose of being and existing as well as the Cognitive structures of leaders.

\begin{tabular}{|l|c|c|c|c|}
\hline & Frequency & Percentage & Agree Percentage & Cumulative Percentage \\
\hline Agree & strongly disagree & 27 & 39.1 & 45.0 \\
\hline 2 & 30 & 43.5 & 50.0 \\
\hline 3 & 3 & 43.0 & 5.0 \\
\hline Total & 60 & 87.0 & 100.0 \\
\hline
\end{tabular}

App Triple loop=radical transformation of the affected system and leadership behaviors.

Table 14: Radical transformation of the affected system and leadership behaviors.

\section{Triple loop organizational learning process}

A strong majority of respondents $86.7 \%$ do not at all agree and disagree on the principle of the questioning of identity, purpose and to exist and their structures cognitive. ( 1 and 2 on a scale of $1=$ not at all agree $/ 5=$ strongly agree) in the same way $95 \%$ have not used or the radical transformation of the affected system or even their behaviors (Tables 13 and 14).

\section{Test Assumptions}

$\mathrm{H}$ : The organizational learning process is a three-dimensional concept

We could, in our discussions, identify several topics related to the concept of the organizational learning

Process. Then, factor analysis performed on the set of the same concept confirmed the three-dimensional structure of the building which is set around three axes:

Axis 1: Learning loop/double questioning and changing objectives (of $\alpha$ Cronbach $=0.822$ )

Axis 2: Learning loop single/maintenance of the system and correction of the error ( $\alpha$ to Cronbach $=0.76$ )

Axis 3: Learning triple loop/questioning of identity
We therefore confirm the criterion of three-dimensionality that we have chosen, the concept of organizational learning crisis, described by Dufort [8]. In the following subsections, we will discuss the content of the three dimensions of the process organizational learning confirmed by factor analysis.

\section{Double loop learning/questioning and changing aims}

Regarding this aspect, the descriptive statistical analysis has allowed us to show that $66.7 \%$ of managers say they have questioned the strategic aims, standards, values and basic assumptions of their organizations. ( 4 and 5 on a scale of $1=$ not at all agree $/ 5=\mathrm{I}$ completely agree). In the same way, $60 \%$ used a modification of the goals of their organizations to realign its perception and its framework for action. Our results verify the principle stipulated by Mason and Mitroff [7] prompting the organization to reconsider its assumptions or underlying assumptions. Our results also confirm the words of Dufort [8] that result in the establishment of a new framework for organizational action, questioning the values implicit reference and changing aims. Our results also confirm about Argyris and Schon [9] which show that double-loop learning is one that induces a change of values, but also strategies and their paradigms [10-13]. The learning process double loop leads to a questioning of values, norms, strategic choices that are upstream and determining the repertoire of an action-taker or action strategies or organization. In the changing, it is possible to generate a 
new repertoire of action strategies that can help to correct the error. In other words, the process double loop occurs through a restructuring process at the origin of our thoughts and our behavior. This level of learning often includes an incremental learning but it goes further [14-17]. This is the level of process analysis, one in which individuals become observers of themselves and wonder (What is the problem?) (What is the process that we must follow?).

\section{Single loop learning/holding system and error correction}

Regarding the second dimension, the descriptive statistical analysis has allowed us to show that a strong majority of respondents $95 \%$ used to maintain the original operating system by adapting gradually to environmental change ( 4 and 5 on a scale of $1=$ not at all agree $/ 5=\mathrm{I}$ completely agree). Similarly, the detection and correction of error, by making minor modifications have been-used by $98.3 \%$ of respondents. $86.7 \%$ of respondents have resorted to the creation of short-term measures, based on pre-established objectives. Furthermore, $71.7 \%$ of respondents were unable to acquire new skills without questioning their framework and their founding beliefs. Our results verify the principle advocated by Dufort [8] which results in maintaining the status while adjusting to changes in the environment and the implementation of short-term measures designed to address shortcomings and deficiencies that obviously have been the reason behind the crisis in accordance with pre-established goals. This learning mode Single loop is the dimension that individuals and organizations activate during simple exercises problem solving. This also allows for the detection and error correction supported by Bateson, Argyris and Schon [6,9].

When there is a gap between intentions and consequences observed that is to say a mistake, then we enter a learning loop. In this perspective, one learns when identifying and correcting this error. The Single loop-Learning, refers to situations where one implements an action strategies available in the existing directory without changing the values, standards, etc. In other words, the process single-loop refers to the acquisition of new skills and abilities through collaboration. This improves without changing or jeopardizing the planned aims [18-20].

\section{Triple loop learning/questioning of identity}

Regarding the third dimension, the descriptive statistical analysis has allowed us to show that a strong majority of respondents $86.7 \%$ do not at all agree and disagree on the principle of questioning the identity, purpose and to exist as well as their cognitive structures (4 and 5 on a scale of $1=$ not at all agree $/ 5=$ I completely agree) in the same way $95 \%$ of participating companies in our study have not resorted to the radical transformation of the system which hasn't affected their behavior. The third dimension of the variable organizational learning process corresponding to factor triple loop learning process, questioning the identity does not check the principle highlighted by Dufort [8] which results in questioning the identity, purpose and existence as an organization, this third dimension showed insignificant results. In other words, the independent variables on the triple loop learning, questioning of identity does not have a significant impact on the third dimension of organizational learning. The triple loop learning processes implies the radical transformation of cognitive structures, the way of thinking, methods of working, and the way to act, to solve problems and manage all critical situations. So what is the total change of the founding values of the organization, thought matrix and cognitive structures of the leaders, by the introduction of new management methods? This is called a seismic change. Change can be gradual or sudden. In the light of these three dimensions we can say that the process of organizational learning post crisis is most often the incremental level that is to say at the first simple loop dimension that results in progressive change and also at the second double loop dimension which is essentially based on the questioning of the context of the organizational action of its founding values and strategic objectives but no level of the third triple loop dimension, because it requires material and physical commitment from leaders and also requires a creative courage of their part in the discovery of new values, new matrices of thought and other management methods [21]. This third level Learning is difficult to achieve because it implies that leaders admit that what they do does not work and that what they face are aspects of their personalities that are not compatible with the image they have of themselves. It is also explained by the lack of commitment, awareness and creative courage from the textile sector companies to discover new values, thought matrix and other management methods.

\section{Conclusion}

After this research devoted to the determination of organizational learning process implemented in post-crisis situations in the textile sector in Tunisia, the analysis has identified:

Three organizational learning processes:

\section{Single loop organizational learning process maintenance of the system and correction of the error}

This is a process that allows organizations to detect and correct errors or deviations and adapt their behavior accordingly to achieve better results.

\section{Double loop organizational learning process/questioning and changing aims}

It is a cognitive Process of questioning of predetermined goals, which led to the adoption and production of new work Methods.

\section{Triple loop organizational learning process questioning of identity}

It is a process leading to the Questioning of identity, purpose and to exist as an organization. This dimension revealed no significant results, in other words the independent variables of the post-crisis behavior have no significant impact on the third dimension of organizational learning. In light of these results, the process of organizational learning the most adopted based on the post-crisis of the textile sector companies surveyed behavior in Tunisia and mainly rely only on two learning process:

- The single loop Organizational Learning Process simply maintaining the system and Error Correction.

- The double loop organizational learning process questioning and changing goals.

The triple loop Organizational Learning Process questioning the identity revealed no significant results and therefore it is not adopted by the textile sector because it requires a radical change in the framework or action of the organization and cognitive structures of executives, identity, purpose and existence as an organization This study could prompt that companies in the textile sector in Tunisia put more emphasis on post-crisis behavior that is essential for its survival and continuity, as well as its influence on the determination of the proper choice of the organizational learning process. The results of this research allow showing the importance of these two learning processes single-loop and double loop in the context of behavioral management in post-crisis situation. This is proved mainly at the dimension "single 
Citation: Skhiri MO (2017) Organizational Learning Process in Single, Double and Triple Loop Companies in a Post-Crisis Situation in the Textile Sector in Tunisia. J Entrepren Organiz Manag 6: 219. doi: 10.4172/2169-026X.1000219

loop Organizational Learning Process system maintenance and correction of the error." Based on our research model and our empirical investigation conducted on a sample of 60 textile companies in Tunisia, these leaders will present a landmark or a position exposing factors and post-crisis behavior of the variables that helps the determination of the proper choice of the organizational learning process. Indeed the hypothesis $\mathrm{Ha}$ and $\mathrm{Hb}$ are checked though partly by our model for the two dimensions of single and double loop organizational learning.

\section{The Recommendations for Tunisian Textile Companies}

The organizations in the textile sector must learn to anticipate and handle situations of crisis and post crisis, using the following key learning tools:

The textile sector organizations need to invest in another form of learning a crisis. Accessing a third form of learning for these companies involves a very important leadership commitment and momentum for change in depth of their identities, their cognitive structures and their purpose to exist as an organization. This level of learning helps the company find creativity, innovation and flexibility, improve the system of prevention and anticipation of crises.

- Adopt the new findings and originality in the study of attacks, threats and weaknesses and vulnerabilities:

To adapt to new types of attacks, the textile business managers must adopt new methods of analysis and risk management.

- Develop flexibility in planning:

It is very difficult to predict all the problems and the entire crisis that will face the organizations of the textile sector in Tunisia. In these circumstances, some experts recommend increasing the flexibility of programs by introducing other improvising to anticipate future crises.

- Improving, prevention and crisis planning:

These organizations in the textile sector must develop innovative approaches to meet the new demands of the crisis. As highlighted Lagadec [22] must think systemically, be prepared to the unthinkable, unpredic in a cross-border logic "the goal is not to predict the unthinkable but being prepared is the 'unthinkable'.

In conclusion, this study aims to provide organizations in the textile sector in Tunisia landmarks, methods and organizational learning process to help executives develop management devices designed to learn and prevent future crises.

\section{References}

1. Shrivastava P (1983) A typology of organizational learning systems. Journal of Management Studies 20: 7-28.
2. Fiol CM, Lyles MA (1985) Organizational learning. Academy of Management Review 10: 803-813.

3. Huber GP (1991) Organizational Learning: the Contributing Processes and the Literatures. Organization Science 2: 88-115

4. Dixon NM (1992) Organizational Learning: Review of the Literature with Implications for HRD Professionals, in Human Resource Development Quarterly 3: 29-49

5. Argyris C, Schon DA (2002) Organizational Learning: A Theory practice, Oxford University Press.

6. Bateson G (1972) Steps to an ecology of mind. The University of Chicago press books.

7. Mitroff II, Mason (1980) R. 0. Structuring ill-structured policy issues: further Top explorations in a methodology for messy problems. Strategic Management Journal 1: 331-342.

8. Duffort CR (2000) Crises learning opportunities for the company, "French Review of Management.

9. Argyris C, Schon DA (1978) Organizational Learning: A Theory of Action Perspective.

10. Argyris C (1993) Knowledge for action, overcoming barriers to organizational learning.

11. Ross WA (1960) Design for a brain. New York Jony willey and Sons, Inc.

12. http://www.artes-research.com/en/speakers-sustexnet-open-seminar/.

13. https://asu.pure.elsevier.com/en/publications/international-handbook-oforganizational-crisis-management.

14. Jean-Luc W, Latiers M (2006) Exploring complex emergency situations' dynamic: theoretical, epistemological and methodological proposals. International Journal of Emergency Management.

15. https://www.ncbi.nlm.nih.gov/pubmed/27286812

16. Churchill GA (1979) A Paradigm for Developing Measures of better marketing constructs. Journal of Marketing Research pp64-73.

17. Gherzi, Organization - Zurich, (2009) And Strategic ude Textile and clothing sector, diagnosis and positioning,Tunisia.

18. https://www.bonusportal.org/files/4699/BONUS_Publication_No_15.pdf.

19. Nowduri S (1985) Management information systems and business decision making: review, analysis, and recommendations. Journal of Management and Marketing Research, pp: 1-8.

20. Mezey G (2004) Crisis, stress and decision-making. 3: 267-288.

21. Huber GP (1984) The nature and design of post-industrial organizations Management Science 30: 928-951.

22. Lagadec P (2002) Crisis management in France: Trends, Shifts and Perspectives. Journal of Contingencies and Crisis Management 10: 159-172. 